\title{
Inflammatory status hepatic enzymes and serum creatinine in HIV-, HIV+ and HIV-TB co-infected adult Central Africans
}

This article was published in the following Dove Press journal:

International Journal of General Medicine

14 November 2012

Number of times this article has been viewed

Etienne Mokondjimobe ${ }^{1,2}$

Benjamin Longo-Mbenza ${ }^{3}$

Patou Mampouya-Arrouse'

Henri Joseph Parra ${ }^{1,2}$

Martin Diatewa'

'Laboratory de Biochemistry-

Pharmacology, Faculty of Health

Sciences, ${ }^{2}$ National Laboratory of

Public Health, Brazzaville, Congo;

${ }^{3}$ Faculty of Health Sciences,

Walter Sisulu University,

Mthatha, South Africa
Correspondence: Benjamin Longo-Mbenza Walter Sisulu University, Faculty of Health Sciences, Private Bag XI, Mthatha 5II7, Eastern Cape,

South Africa

Tel +27 732822843

$\mathrm{Fax}+27475022101$

Email longombenza@gmail.com
Background and aim: Human immunodeficiency virus (HIV)/acquired immunodeficiency syndrome is a major public health issue in Africa. The objective of this study was to determine which of isolated HIV-infection, isolated naive pulmonary tuberculosis (PTB), or naive HIV-PTB coinfection was more harmful to inflammatory, hepatic, and renal functions.

Methods: This cross-sectional study was undertaken among ten patients with isolated HIV infection, ten patients with isolated naive HIV infection, ten patients with isolated PTB and 32 patients with HIV-PTB coinfection, with the aim of determining which group had the highest levels of oxidative stress and hepatic and renal dysfunction markers. Serum aminotransferase (AST), alanine transferase (ALT), gamma-glutamyl transferase (GGT), and creatinine measurements were compared across the three groups of patients, who were managed from admission in the pulmonology division of the Brazzaville Teaching Hospital, Congo.

Results: HIV patients had the highest levels of ALT, GGT, and creatinine before and after adjusting for age and sex. Adjusted levels of AST, ALT, GGT, and creatinine were higher in HIV-PTB coinfection patients than in sero-negative PTB patients.

Conclusion: There is a significant association between HIV infection and increase in concentration of ALT, GGT, and creatinine.

Keywords: Africa, tuberculosis, HIV-tuberculosis coinfection, renal function

\section{Background}

It is well-known that the HIV/AIDS pandemic is responsible for the resurgence of tuberculosis (TB), with increased morbidity and mortality worldwide. ${ }^{1}$ Developing settings such as sub-Saharan Africa and South-East Asia are most vulnerable to this pandemic. ${ }^{1}$

The HIV/AIDS pandemic has led to $9 \%$ of all new TB cases worldwide, $31 \%$ of which are in Africa. ${ }^{2} \mathrm{~TB}$ is the top cause of morbidity and mortality in patients suffering from HIV/AIDS. ${ }^{3,4}$ There is a synergistic interaction between HIV and Mycobacterium tuberculosis, with each accentuating the progression of the other. ${ }^{5-7}$

In patients with $\mathrm{TB}$, acute renal failure is one of the factors significantly and independently associated with mortality. ${ }^{8}$ Renal structure and function are often compromised in HIV/AIDS patients. ${ }^{9-11}$

Mortality is higher among HIV/AIDS patients not on antiretroviral therapy and those with elevated liver enzymes. ${ }^{12}$ A recently published prospective study from Uganda showed that cumulated mortality among HIV-infected patients diagnosed with TB at baseline or follow-up was higher than in those HIV-infected patients without TB. ${ }^{13}$ Moreover, markers of inflammation are present in atherosclerotic populations. ${ }^{14}$ 
Alanine aminotransferase (ALT) and gamma-glutamyl transferase (GGT) are now considered markers of inflammation with immune dysfunction in HIV $^{15}$ and oxidative stress. ${ }^{16} \mathrm{HIV}$ infection results from chronic immune system activation and inflammatory cytokine release.

In terms of outcome, the mortality of HIV-infected patients with TB is comparatively higher than that of HIV-negative TB patients. ${ }^{17}$ Recent developments have focused on ongoing challenges in the pathophysiology, diagnosis, and treatment of HIV-related kidney disease. ${ }^{18}$ However, no baseline data on oxidative inflammatory hepatic and renal functions according to HIV status, TB, and their concurrence are available. Thus, the present research aimed to determine which of isolated naive HIV-infection, isolated naive pulmonary TB (PTB), or naive HIV-PTB coinfection is more harmful on inflammatory, hepatic, and renal functions.

\section{Materials and methods}

This cross-sectional and comparative study, approved by the local Research Ethics Committee of the Marien Ngouabi University, Brazzaville, Republic of Congo, was conducted in March, randomly selected from 2006 to 2011.

The study was undertaken according to the Helsinki declaration after written consent was obtained from consecutive adult patients managed within the division of Infectious Diseases at Brazzaville Teaching Hospital.

Inclusion criteria included admission for naive isolated PTB, naive isolated HIV-infected, and HIV-PTB coinfection. Exclusion criteria were: age $<18$ years; hepatitis; cigarette smoking; history of drug and/or alcohol abuse (defined as $\geq 4$ drinks/day in men and $\geq 3 \mathrm{drinks} /$ day in women), previous anti-TB therapy or antiretroviral treatment; viral hepatitis A, $\mathrm{B}, \mathrm{C}$, or E; and Epstein-Barr virus.

From 60 eligible patients, 52 were accepted into the study (response rate of $86.6 \%$ ).

Diagnosis of PTB was based on the WHO criteria: a positive culture for Mycobacterium tuberculosis or negative culture associated with clinical and radiological features. ${ }^{19}$ Diagnosis of HIV-infection was based on clinical criteria from $\mathrm{WHO}^{20}$ and the Centers for Disease Control and Prevention. ${ }^{21}$ The patients with AIDS had a CD4 count of $<200$.

Demographic characteristics (age, sex, sex ratio) and laboratory measurements were obtained from the patients. Serum liver enzymes (AST, ALT, and GGT) were measured for hepatic function, while serum creatinine was measured for renal function, using drawn venous blood at admission and after a 10-hour overnight fasting. Venous blood samples were collected for quantitative C-reactive protein (CRP) analysis using TURBILYTE-CRPs (Tulip Diagnostics, Goa, India) according to the manufacturer's instructions, with a detection limit of $0.5 \mathrm{mg} / \mathrm{L}$ and measuring range of $0-22 \mathrm{mg} / \mathrm{L}$.

The serum was separated after centrifugation of the blood and kept frozen at $-20^{\circ} \mathrm{C}$ before analysis at the National Laboratory of Public Health in Brazzaville, Republic of Congo.

Serum AST was evaluated by a kinetic determination: malate dehydrogenase was used to catalyze the reaction between oxaloacetic acid and $\beta-\mathrm{NADH}_{2}$, forming lactic acid and $\beta$-NAD. Serum ALT was also evaluated by a kinetic determination: lactate dehydrogenase was used to catalyze the reaction between pyruvic acid and $\beta-\mathrm{NADH}_{2}$, forming lactic acid and $\beta$-NAD. Serum GGT was evaluated using an enzymatic colorimetric method. Finally, serum creatinine was measured using an alkaline picrate method developed by Jaffe two centuries ago and modified for routine practice in sub-Saharan Africa. ${ }^{22}$

All laboratory measurements were performed using bioMérieux reagents and an automated analyzer, using the VIDAS TPSA kit (bioMérieux, Marcy l'Etoile, France). The inter-assay coefficients of variation of these laboratory measurements were as follows: AST, 0.8\%; ALT, 0.5\%; GGT, 0.6\%; and creatinine, $1.1 \%$. These were within the $0.87 \%-2.1 \%$ interval.

\section{Statistical analysis}

The data were expressed as frequency, ratio, and proportions for qualitative variables and as mean \pm standard deviation (SD) for continuous variables.

One-way analysis of variance (ANOVA) with Bonferroni post-hoc test for multiple comparisons was used to compare the means of AST, GGT, CRP, and creatinine across the study groups before and after adjusting for sex and age. A $P$ value $<0.05$ was considered statistically significant. SPSS $^{\circledR}$ software for Windows (v 19.0; SPSS Inc, Chicago, IL) was used for analysis of data.

\section{Results}

\section{Patient characteristics}

Demographic and clinical characteristics for the 52 patients included in the study are shown in Table 1. There was a predominance of females, with a female to male ratio of $3: 1$ in average; $4: 1$ in the naive HIV-PTB coinfection and 2:1 in isolated naive HIV sero-positive groups. However, there was a predominance of males, with a male to female ratio of $2: 1$, in the isolated naive PTB group. Two-thirds of the participants had naive HIV-PTB coinfection. 
Table I Demographic and clinical characteristics of the study population

\begin{tabular}{lll}
\hline Variables & Nor mean \pm SD & $\%$ \\
\hline Gender & & \\
$\quad$ Male & 13 & 25 \\
$\quad$ Female & 39 & 75 \\
Age (years) & $37 \pm 10.8$ & \\
Groups & & 61.5 \\
$\quad$ HIV and PTB coinfection & 32 & 19.2 \\
HIV+ and PTB- & 10 & 19.2 \\
PTB+ and HIV- & 10 & \\
\hline
\end{tabular}

Abbreviations: HIV, human immunodeficiency virus; PTB, pulmonary tuberculosis; $\mathrm{SD}$, standard deviation.

\section{Comparisons}

Table 2 compares the mean values of age, AST, ALT, GGT, CRP, and creatinine, which varied significantly (ANOVA: $P<0.05)$ across the groups. The highest age and levels of ALT, GGT, creatinine, and CRP were observed in HIV+ and PTB-patients. However, the highest mean AST was in HIV- and PTB+ patients.

After adjusting for age and sex (Table 3), the means of AST, ALT, GGT, CRP, and creatinine varied highly significantly $(P<0.01)$ across the study groups. The highest concentrations of ALT, GGT, creatinine, and CRP were reported among naive HIV+ patients, while the highest level of AST was in patients with HIV-PTB coinfection.

\section{Discussion}

The present study demonstrated that isolated naive infection was associated with higher levels of ALT, GGT, and creatinine before and after adjusting for age and sex.

However, isolated naive HIV-PTB coinfection patients had higher levels of AST, ALT, GGT, and creatinine than naive PTB patients without HIV infection.

In sub-Saharan Africa, females are more likely to use medical facilities than males. On this continent, however, males have

Table 2 Comparisons of characteristics across the groups without adjusting for age and sex

\begin{tabular}{lccc}
\hline Variables & $\begin{array}{l}\text { HIV+ and } \\
\text { PTB+, } \\
\mathbf{n = 3 2} \text { naive }\end{array}$ & $\begin{array}{l}\text { HIV+ and } \\
\text { PTB-, } \\
\mathbf{n}=\mathbf{~ I 0}\end{array}$ & $\begin{array}{l}\text { HIV- and } \\
\text { PTB+, } \\
\mathbf{n}=\mathbf{~ I 0}\end{array}$ \\
\hline Age (years) & $37 \pm 10.8$ & $38 \pm 10.5$ & $32 \pm 8.5$ \\
AST (U/L) & $7.7 \pm 4.9$ & $8.7 \pm 4.5$ & $15.7 \pm 10.8$ \\
ALT (U/L) & $11.2 \pm 6.2$ & $27.5 \pm 5.5$ & $9.1 \pm 8.1$ \\
GGT (U/L) & $42.5 \pm 10$ & $55.6 \pm 10.2$ & $32.3 \pm 5.1$ \\
Creatinine (mg/dL) & $0.6 \pm 0.3$ & $1.5 \pm 0.5$ & $1.3 \pm 0.4$ \\
CRP (mg/L) & $7.6 \pm 2.6$ & $22.4 \pm 3.4$ & $17.6 \pm 2.9$ \\
\hline
\end{tabular}

Abbreviations: ALT, alanine transferase; AST, aminotransferase; CRP, C-reactive protein; GGT, gamma-glutamyl transferase; HIV, human immunodeficiency virus; PTB, pulmonary tuberculosis.
Table 3 Comparisons of characteristics across the study groups after adjusting for age and sex

\begin{tabular}{lcrc}
\hline Variables & $\begin{array}{l}\text { Naive HIV-PTP } \\
\text { coinfection }\end{array}$ & Naive HIV+ & Naive PTB \\
\hline AST (U/L) & $15 \pm 5$ & $9 \pm 4.8$ & $13.2 \pm 9$ \\
ALT (U/L) & $13.2 \pm 5$ & $29.4 \pm 7.2$ & $8.3 \pm 6.4$ \\
GGT (U/L) & $44.5 \pm 1 \mathrm{I}$ & $59.7 \pm 9.5$ & $30 \pm 4.9$ \\
Creatinine (mg/dL) & $1.4 \pm 0.4$ & $2.1 \pm 0.6$ & $1.2 \pm 0.3$ \\
CRP (mg/L) & $13.8 \pm 5.3$ & $45.7 \pm 6.9$ & $34.6 \pm 4.8$ \\
\hline
\end{tabular}

Abbreviations: ALT, alanine transferase; AST, aminotransferase; CRP, C-reactive protein; GGT, gamma-glutamyl transferase; HIV, human immunodeficiency virus; PTB, pulmonary tuberculosis.

a higher prevalence of TB infection than females, ${ }^{23}$ a tendency reflected in this study.

\section{HIV infection and laboratory data}

Patients with isolated naive HIV infection were older than the rest of the participants. This may explain the positive and significant association between higher levels of ALT, GGT, and HIV infection itself. Aging is related to oxidative stress $^{24}$ and decline in renal function.

Coupled with the aging process, the extended exposure of these adults to HIV, the persistent activation of immune cells by the virus, inflammation, and oxidative stress related to HIV-infection, ${ }^{15}$ will probably mean that they have increased risk of impaired kidney function compared with their nonHIV-infected counterparts. ${ }^{9-11,25,26}$

Antiretroviral treatment might suppress HIV replication, with a reduction in HIV-related mortality, opportunistic disease, malignancy, cardiovascular disease, and metabolic, bone, renal and liver diseases, not unlike that in aging patients. ${ }^{25} \mathrm{CRP}$ is not known as a biomarker of inflammation in HIV-related morbidity. ${ }^{15}$

\section{Clinical implications}

The present study emphasizes the need for a resourceappropriate screening algorithm for inflammatory hepatic and renal disease biomarkers, both as part of anti-TB and antiretroviral therapy eligibility and pretreatment assessment.

HIV/AIDS is associated with both direct (HIV-associated nephropathy) and indirect (opportunistic infections such as TB and HIV-hepatitis C coinfection as well as medicationrelated) renal complications.

HIV and HIV-PTB coinfection pose a risk to older individuals, with potential complex treatment challenges. Therefore, older adult at risk need to get tested for the virus and take steps to protect themselves and their loved 
ones from becoming infected. Research is needed to help health professionals tackle the often-complicated treatment of HIV infection, PTB, and related illnesses in older patients.

In case of diagnosis of renal failure of unknown etiology, provision of antiretroviral therapy may improve renal function. ${ }^{27-30}$

HIV-infected patients do respond well to the standard 6-month anti-TB therapy. ${ }^{5}$ Guidelines for the management of HIV-TB coinfection are still evolving. Timely anti-TB and antiretroviral treatment may improve the outcomes of HIVPTB coinfection. ${ }^{5}$ However, pharmacokinetic interactions occur between rifampicin and protease inhibitors, and nonnucleoside reverse transcriptase. ${ }^{31-35}$ Our findings recommend that all PTB patients should be tested for HIV. ${ }^{36}$

\section{Study limitations}

It should be acknowledged that these findings apply only to this small group of selected patients and generalization to other series might be premature in the absence of additional data to confirm the results of this study. In addition, the cross-sectional design limits the conclusion with regard to the causal association of HIV itself or HIV-PTB coinfection with oxidative stress and hepatic and renal function markers.

Diet, ethnicity and lean mass may impact on the values of renal function in HIV and PTB coinfection. ${ }^{37}$

These limitations not withstanding, the findings of the present study have practical implications for managing HIVinfected patients and patients with HIV-PTB coinfection in Brazzaville, Republic of Congo.

In the future, there is a need to adjust for right inflammation markers, hepatic and creatinine concentrations.

\section{Conclusion}

This study found a significant association between HIV infection and an increase in serum levels of ALT, CRP, GGT, and creatinine.

\section{Disclosure}

The authors declare no conflicts of interest in this work.

\section{References}

1. Joint United Nations Programme on HIV/AIDS (UNAIDS), World Health Organization (WHO). AIDS Epidemic Update: December 2004. UNAIDS/04.45E. Geneva: UNAIDS; 2004.

2. Corbett EL, Watt CJ, Walker N, et al. The growing burden of tuberculosis: global trends and interactions with the HIV epidemic. Arch Intern Med. 2003;163(9):1009-1021.

3. Raviglione MC, Narain JP, Kochi A. HIV-associated tuberculosis in developing countries: clinical features, diagnosis and treatment. Bull World Health Organ. 1992;70(4):515-525.
4. WHO. TB/HIV: A Clinical Manual, 2nd ed. Geneva: WHO; 2004.

5. Sharma SK, Mohan A, Kadhiravan T. HIV-TB co-infection: epidemiology, diagnosis and management. Indian J Med Res. 2005; 121(4):550-567.

6. Havlir DV, Barnes PF. Tuberculosis in patients with human immunodeficiency virus infection. $N$ Engl J Med. 1999;340(5): 367-373.

7. Liberato IR, de Albuquerque Mde F, Campelo AR, de Melo HR. Characteristics of pulmonary tuberculosis in HIV seropositive and seronegative patients in a Northeastern region of Brazil. Rev Soc Bras Med Trop. 2004;37(1):46-50.

8. Erbes R, Oettel K, Raffenberg M, Mauch H, Schmidt-Ioanas M, Lode H. Characteristics and outcome of patients with active pulmonary tuberculosis requiring intensive care. Eur Respir J. 2006;27(6): $1223-1228$.

9. Nseka Mangani N, Nyimi Malonda L, Longo-Mbenza B. De la sémiologie et du traitement des manifestations rénales par l'infection VIH-1. Semiology and treatment of renal manifestations in HIV-1 infection. Médecine d'Afrique Noire. 1996;43(2):92-95. French.

10. Isa WY, Daud KM. Distal renal tubular acidosis in HIV/AIDS patient. Intern Med. 2011;50(16):1765-1768.

11. George E, Lucas GM, Nadkarni GN, Fine DM, Moore R, Atta MG. Kidney function and the risk of cardiovascular events in HIV-1-infected patients. AIDS. 2010;24(3):387-394.

12. Rajagopalan N, Suchitra JB, Shet A, et al. Mortality among HIVinfected patients in resource limited settings: a case controlled analysis of inpatients at a community care center. Am J Infect Dis. 2009;5(3): 219-224.

13. WHO. Antiretroviral Therapy for HIV Infection in Adults and Adolescents: Recommendations for a Public Approach. Geneva: WHO; 2006.

14. Arnett DK, McClelland RL, Bank A, et al. Biomarkers of inflammation and hemostasis associated with left ventricular mass: The Multiethnic Study of Atherosclerosis (MESA). Int J Mol Epidemiol Genet. 2011;2(4): 391-400.

15. Nixon DE, Landay AL. Biomarkers of immune dysfunction in HIV. Curr Opin HIV AIDS. 2010;5(6):498-503.

16. Yamada J, Tomiyama H, Yambe H, et al. Elevated serum levels of alanine aminotransferase and gamma-glutamyl transferase are markers of inflammation and oxidative stress independent of the metabolic syndrome. Atherosclerosis. 2006;189(1):198-205.

17. Kang'ombe CT, Harries AD, Ito K, et al. Long-term outcome in patients registered with tuberculosis in Zomba, Malawi: mortality at 7 years according to initial HIV status and type of TB. Int J Tuberc Lung Dis. 2004;8(7):829-836.

18. Estrella MM, Fine DM, Atta MG. Recent developments in HIV-related kidney disease. HIV Ther. 2010;4(5):589-603.

19. WHO Global Tuberculosis Programme. Treatment of Tuberculosis: Guidelines for National Programmes, 3rd ed. Geneva: WHO; 2003.

20. Interim proposal for a WHO staging system for HIV infection and disease. Wkly Epidemiol Rec. 1990;65(29):221-224.

21. 1993 revised classification system for HIV infection and expanded surveillance case definition for AIDS among adolescents and adults. MMWR Recomm Rep. 1992;41(RR-17):1-19.

22. Afolabi MO, Abioye-Kutey EA, Arogundade FA, Bello IS. Prevalence of chronic Kidney disease in a Nigerian family practice population. $S A$ Fam Pract. 2009;51(2):132-137.

23. Nwachukwu NC, Orji A, Kanu I, Okereke HC. Epidemiology of pulmonary tuberculosis in some parts of Abia State, Federal Republic of Nigeria. Asian J Epidemiology. 2009;2(1):13-19.

24. Alsxeyev MF. Is there more to aging than mitochondrial DNA and reactive oxygen species? FEBS J. 2009;276(20):5768-5787.

25. Deeks SG, Phillips AN. HIV infection, antiretroviral treatment, ageing and non-AIDS related morbidity. BMJ. 2009;338:a3172.

26. Desquilbet L, Jacobson LP, Fried LP, et al; Multicenter AIDS Cohort Study. HIV-1 infection is associated with an earlier occurrence of a phenotype related to frailty. J Gerontol A Biol Sci Med Sci. 2007;62(11): 1279-1286. 
27. Mulenga LB, Kruse G, Lakhi S, et al. Baseline renal insufficiency and risk of death among HIV-infected adults on antiretroviral therapy in Lusaka, Zambia. AIDS. 2008;22(14):1821-1827.

28. Mayer KH, Szczech LA. Renal diseases associated with human immunodeficiency virus infection: epidemiology, clinical course, and management. Clin Infect Dis. 2001;33(1):115-119.

29. Franceschini N, Napravnik S, Finn WF, Szczech LA, Eron JJ Jr. Immunosuppression, hepatitis C Infection, and acute renal failure in HIV-infected patients. J Acquir Immune Defic Syndr. 2006;42(3): 368-372.

30. Peters PJ, Moore DM, Mermin J, et al. Antiretroviral therapy improves renal function among HIV-infected Ugandans. Kidney Int. 2008;74(7): 925-929.

31. Hakim JG, Ternouth I, Musharngi E, Siziya S, Robertson V, Malin A. Double blind randomised placebo controlled trial of adjunctive prednisolone in the treatment of effusive tuberculous pericaditis in HIV seropositive patients. Heart. 2000;84(2):183-188.

32. Eustace JA, Nuemberger E, Choi M, Scheel PJ Jr, Moore R, Briggs WA. Cohort study of the treatment of severe HIV-associated nephropathy with corticosteroids. Kidney Int. 2000;58(3):1253-1260.
33. Wei A, Burns GC, Williams BA, Mohammed NB, Visintainer P, Sivak SL. Long-term renal survival in HIV-associated nephropathy with angiotensin-converting enzyme inhibition. Kidney Int. 2003;64(4): 1462-1471.

34. Piscitelli SC, Gallicano KD. Interactions among drugs for HIV and opportunistic infections. N Engl J Med. 2001;344(13):984-996.

35. Peake M, Whiting M. Measurement of serum creatinine-current status and future goals. Clin Biochem Rev. 2006;27(4):171-184.

36. Tuberculosis and human immunodeficiency virus infection: recommendations of the Advisory Committee for the Elimination of Tuberculosis (ACET). MMWR Morb Mortal Wkly Rep. 1989;38(14): 236-238, 243-250.

37. Cohen SD, Kimmel PL. HIV-associated renal disease in Africa a desperate need for additional study. Nephrol Dial Transplant. 2007; 22(8) 2116-2119.
International Journal of General Medicine

\section{Publish your work in this journal}

The International Journal of General Medicine is an international, peer-reviewed open-access journal that focuses on general and internal medicine, pathogenesis, epidemiology, diagnosis, monitoring and treatment protocols. The journal is characterized by the rapid reporting of reviews, original research and clinical studies across all disease areas.

\section{Dovepress}

A key focus is the elucidation of disease processes and management protocols resulting in improved outcomes for the patient.The manuscript management system is completely online and includes a very quick and fair peer-review system. Visit http://www.dovepress.com/ testimonials.php to read real quotes from published authors.

Submit your manuscript here: http://www.dovepress.com/international-journal-of-general-medicine-journal 